\title{
ARTICLE
}

\section{Nanoparticle-induced unusual melting and solidification behaviours of metals}

\author{
Chao Ma ${ }^{1,2}$, Lianyi Chen ${ }^{1,3}$, Chezheng $\mathrm{Cao}^{4} \&$ Xiaochun $\mathrm{Li}^{1,4}$
}

Effective control of melting and solidification behaviours of materials is significant for numerous applications. It has been a long-standing challenge to increase the melted zone (MZ) depth while shrinking the heat-affected zone (HAZ) size during local melting and solidification of materials. In this paper, nanoparticle-induced unusual melting and solidification behaviours of metals are reported that effectively solve this long-time dilemma. By introduction of $\mathrm{Al}_{2} \mathrm{O}_{3}$ nanoparticles, the $\mathrm{MZ}$ depth of $\mathrm{Ni}$ is increased by $68 \%$, while the corresponding HAZ size is decreased by $67 \%$ in laser melting at a pulse energy of $0.18 \mathrm{~mJ}$. The addition of $\mathrm{SiC}$ nanoparticles shows similar results. The discovery of the unusual melting and solidification of materials that contain nanoparticles will not only have impacts on existing melting and solidification manufacturing processes, such as laser welding and additive manufacturing, but also on other applications such as pharmaceutical processing and energy storage.

\footnotetext{
${ }^{1}$ Department of Mechanical and Aerospace Engineering, University of California at Los Angeles, Los Angeles, California 90095, USA. ${ }^{2}$ Department of Engineering Technology and Industrial Distribution, Texas A\&M University, College Station, Texas 77843, USA. ${ }^{3}$ Department of Mechanical and Aerospace Engineering, Missouri University of Science and Technology, Rolla, Missouri 65409, USA. ${ }^{4}$ Department of Materials Science and Engineering, University of California at Los Angeles, Los Angeles, California 90095, USA. Correspondence and requests for materials should be addressed to X.L. (email: xcli@seas.ucla.edu).
} 
$\mathrm{M}$ elting and solidification are important in the geophysical sciences, food and pharmaceutical processing, energy storage, materials processing and manufacturing 1 . It is thus of scientific and technical interests to control melting and solidification processes. There exists a long-standing dilemma in melting-based processes, such as welding, cladding, surface alloying and additive manufacturing. With the same energy input, a deeper melted zone (MZ) is desired because the material in MZ is well processed, which provides high material performance. In the meantime, a minimal heat-affected zone (HAZ) is ideal because the dissipated heat coarsens the microstructure, which deteriorates the material properties in the $\mathrm{HAZ}^{2}$. However, a large MZ generally requires a high energy input and thereby induces a large HAZ, which has remained as a critical challenge in melting-based materials processing technologies. Laser materials processing is used as an example to demonstrate the feasibility of the proposed methodology to solve this dilemma because lasers have been used for manufacturing for decades and have brought remarkable impacts in industries $^{3}$. For example, laser welding has been used for the production of car bodies, railway vehicles and ship structures, providing not only technical advantages, such as deep penetration and full automation, but also economic benefits, such as high efficiency and reliability ${ }^{4}$.

This study is also motivated by the substantial interest in the development of metal matrix nanocomposites (MMNCs), that is, metals containing nanoparticles. There has been an explosive growth in research on MMNCs to unleash their unusual properties for widespread applications ${ }^{5-13}$. It is of interest to use lasers to manufacture and process MMNCs. For example, there is fast-growing research on laser additive manufacturing processes for MMNC products ${ }^{14-17}$. However, most previous research focused on the mechanical properties changed by nanoparticles while little fundamental understanding has been obtained on the underlining physics of the process.

In the present work, the contradiction between the desired deep MZ and small HAZ is solved by introducing nanoparticles to metals to tune the melting and solidification behaviours. This work is focused on the specific effects of nanoparticles on the heat transfer, melt pool flow and microstructure evolution during laser melting and solidification processes. The nanoparticles are found to increase the MZ while significantly decreasing the HAZ, which tackles a critical challenge in laser manufacturing and other similar processes.

\section{Results}

Microstructure. Pure $\mathrm{Ni}$ and $\mathrm{Ni} / \mathrm{Al}_{2} \mathrm{O}_{3}$ nanocomposite samples were prepared by electrodeposition and then laser melted using identical parameters. The experimental details are described in the 'Methods' section. The scanning electron microscopy (SEM) images of the $\mathrm{Ni} / \mathrm{Al}_{2} \mathrm{O}_{3}$ surface before and after laser melting at a pulse energy of $0.18 \mathrm{~mJ}$ are shown in Fig. 1 . The relatively bright phases are the well-dispersed $\mathrm{Al}_{2} \mathrm{O}_{3}$ nanoparticles. The dark phase is the Ni matrix. The fraction of $\mathrm{Al}_{2} \mathrm{O}_{3}$ nanoparticles is 4.4 vol. $\%$ and the average diameter is $50 \mathrm{~nm}$. The volume fraction decreased after laser melting. It is possible that some $\mathrm{Al}_{2} \mathrm{O}_{3}$ nanoparticles have been decomposed or ejected from the melt pool.

For further characterization, the cross-sections of the laser melted samples were cut using focused ion beam (FIB). The SEM and FIB micrographs of the cross-sections of $\mathrm{Ni}$ and $\mathrm{Ni} / \mathrm{Al}_{2} \mathrm{O}_{3}$ after laser melting are shown in Fig. 2. It should be noted that the thin layer at the very top is a platinum coating deposited before FIB cutting to protect the surface of interest. As shown in Fig. 2a,b, the microstructure of the laser melted zone is different from the unmelted zone for both the materials. In the pure $\mathrm{Ni}$ sample, there exist many tiny granular features induced by the laser melting process. In the $\mathrm{Ni} / \mathrm{Al}_{2} \mathrm{O}_{3}$ nanocomposite sample, the amount of nanoparticles in the melted zone is less than in the unmelted zone, which agrees with the surface characterization results in Fig. 1. The boundaries are marked by white dashed lines in the images. The melt depth of the $\mathrm{Ni} / \mathrm{Al}_{2} \mathrm{O}_{3}$ nanocomposite, $3.2 \pm 0.2 \mu \mathrm{m}$, is much deeper than that of pure Ni, $1.9 \pm 0.2 \mu \mathrm{m}$.

Ion beam can induce channelling contrast from different grains because the penetration of the ions depends on the crystallographic orientation of each grain, which makes FIB a powerful tool to characterize grain structures. Figure $2 \mathrm{c}$ and $\mathrm{d}$ show the FIB micrographs of the $\mathrm{Ni}$ and $\mathrm{Ni} / \mathrm{Al}_{2} \mathrm{O}_{3}$ cross-sections. Three zones can be identified based on the difference in grain structures from the top to the bottom: (i) large tilted grains, (ii) large vertical grains and (iii) small vertical grains. The first region is the melted zone (MZ), in which the tilted grains due to the asymmetric heating/cooling from the raster scan of the laser. The MZ depths recognized in the FIB images (Fig. $2 c, d$ ) are consistent with those from the SEM graphs (Fig. 2a,b). The second region is identified as the heat-affected zone (HAZ), in which the grains are significantly coarsened compared with the original microstructure. The third region is the base material, which remains as the unaffected electrodeposited structures. The boundaries for these three zones are shown as white dashed lines. The HAZ size of $\mathrm{Ni} / \mathrm{Al}_{2} \mathrm{O}_{3}, 2.7 \pm 0.2 \mu \mathrm{m}$, is remarkably smaller than that of $\mathrm{Ni}$, $8.1 \pm 0.3 \mu \mathrm{m}$.

To understand the nanoparticle-enabled stabilization of microstructure in the $\mathrm{HAZ}$, the grain growth behaviour of $\mathrm{Ni} / \mathrm{Al}_{2} \mathrm{O}_{3}$ nanocomposite was investigated by transmission electron microscopy (TEM) facilitated with in situ heating. Figure $3 \mathrm{a}$ shows the microstructure of the as-deposited $\mathrm{Ni} / \mathrm{Al}_{2} \mathrm{O}_{3}$. The grain structure of $\mathrm{Ni}$ is columnar due to the one-dimensional growth during electrodeposition. The grain structure remained columnar when the sample was heated to 200,400 and $600^{\circ} \mathrm{C}$, as shown in Fig. $3 \mathrm{~b}-\mathrm{d}$, respectively, which indicates the grain structure of $\mathrm{Ni} / \mathrm{Al}_{2} \mathrm{O}_{3}$ is thermally stable at temperature up to $600^{\circ} \mathrm{C}$. However, when the temperature increased to $800^{\circ} \mathrm{C}$, recrystallization occurred as shown in Fig. 3e. The columnar grain boundaries vanished and the grains transformed to equiaxed grains after holding the sample at $800^{\circ} \mathrm{C}$ for about $1 \mathrm{~min}$ as seen in Fig. 3f (the image was taken from a lower magnification than other ones to show a larger field). The grains also grew in the through-thickness direction, which resulted in the size reduction of the sample in the view plane. The grain growth temperature of $\mathrm{Ni} / \mathrm{Al}_{2} \mathrm{O}_{3}$ is significantly higher than that of $\mathrm{Ni}, 418^{\circ} \mathrm{C}$ (ref. 18), due to the fact that the $\mathrm{Al}_{2} \mathrm{O}_{3}$ nanoparticles effectively inhibit the grain growth. This explains why a large reduction in HAZ was obtained.

Numerical simulation. Recent studies have shown that thermophysical properties (for example, thermal conductivity, surface tension and viscosity) of a material can be altered by addition of nanoparticles ${ }^{19-22}$. Since a melting process is determined by the thermophysical properties, it is highly possible that the nanoparticle-modified thermophysical properties induced the deeper melting pool. To better understand why nanoparticles induced a smaller HAZ but a deeper MZ, the effects of nanoparticles on optical and thermophysical properties were measured with the experimental methods developed recently ${ }^{23,24}$. All the properties that are essential to study laser interaction with nanocomposites were determined, including optical reflectivity, heat capacity, thermal conductivity, surface tension and dynamic viscosity. To show the difference in the properties between $\mathrm{Ni}$ and $\mathrm{Ni} / \mathrm{Al}_{2} \mathrm{O}_{3}$, the measured material properties are normalized using 
a

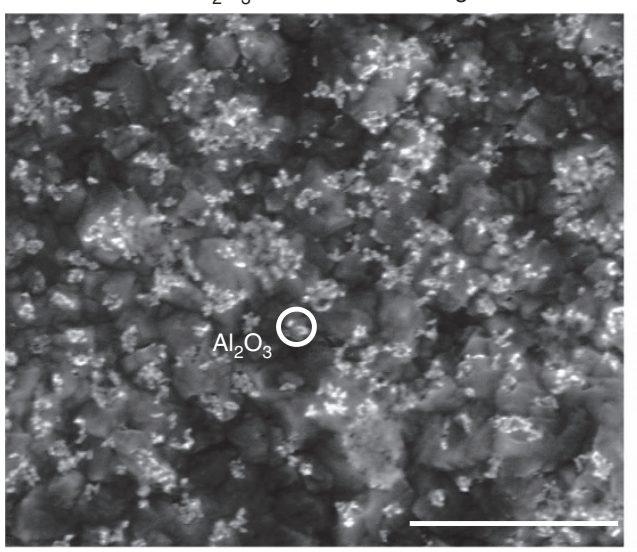

b

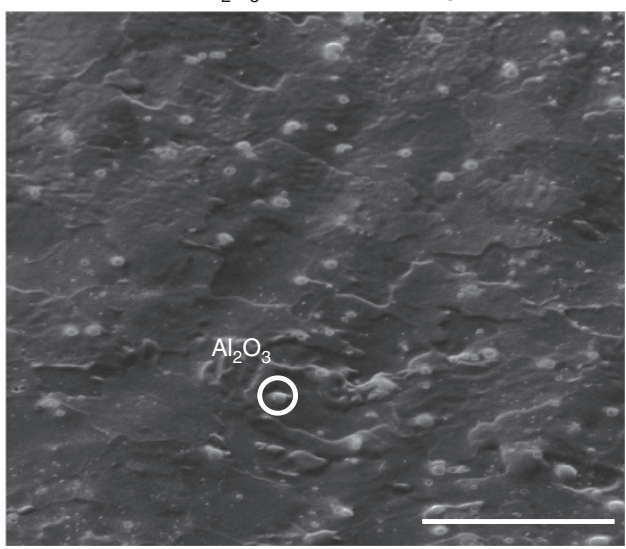

Figure 1 | Characterization of $\mathbf{N i} / \mathbf{A l}_{\mathbf{2}} \mathbf{O}_{\mathbf{3}}$ surface. Scanning electron microscopy (SEM) images before (a) and after (b) laser melting at a pulse energy of $0.18 \mathrm{~mJ}$. The bright granular phases are the $\mathrm{Al}_{2} \mathrm{O}_{3}$ nanoparticles while the continuous dark phase is the Ni matrix. The nanoparticles are well dispersed and uniformly distributed in the matrix. Scale bars, $1 \mu \mathrm{m}$ in $\mathbf{a}$ and $2 \mu \mathrm{m}$ in $\mathbf{b}$.

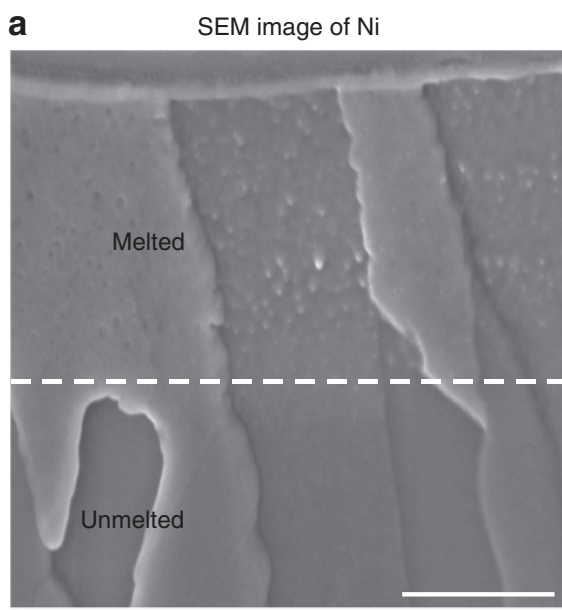

b SEM image of $\mathrm{Ni} / \mathrm{Al}_{2} \mathrm{O}_{3}$
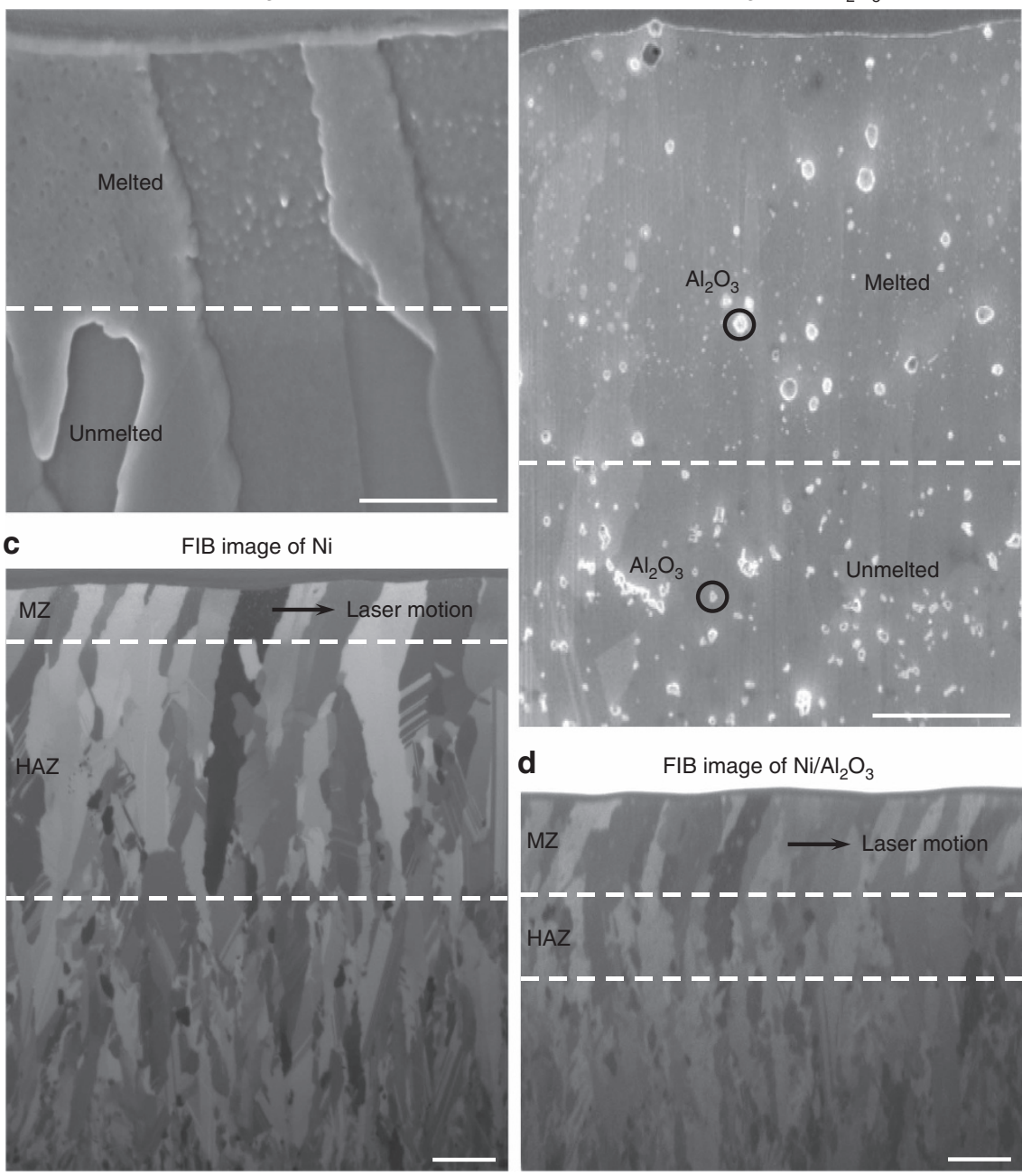

d

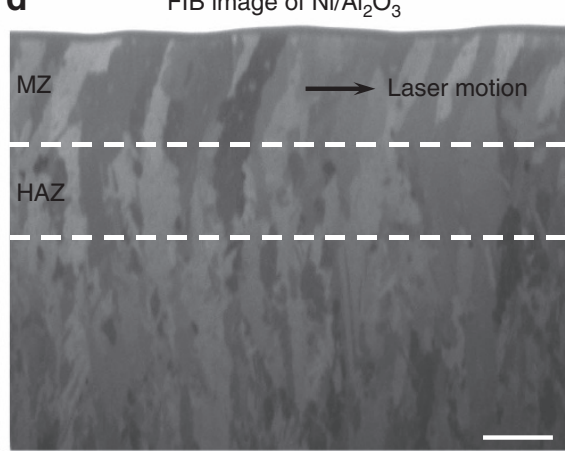

Figure 2 | Characterization of $\mathbf{N i}$ and $\mathbf{~ N i} / \mathbf{A l}_{\mathbf{2}} \mathbf{O}_{\mathbf{3}}$ cross-sections. Scanning electron microscopy (SEM) images of $\mathrm{Ni}(\mathbf{a})$ and $\mathrm{Ni} / \mathrm{Al}_{2} \mathrm{O}_{3}(\mathbf{b})$ that were laser melted at a pulse energy of $0.18 \mathrm{~mJ}$ and the corresponding focused ion beam (FIB) micrographs of $\mathrm{Ni}(\mathbf{c})$ and $\mathrm{Ni} / \mathrm{Al}_{2} \mathrm{O}_{3}(\mathbf{d})$. The $\mathrm{SEM}$ images show the different microstructures between the melted and unmelted zones. The FIB images show the distinct grain structures among the melted zone (MZ), heataffected zone (HAZ) and the base material. The $\mathrm{MZ}$ of Ni/Al $\mathrm{O}_{2} \mathrm{O}_{3}$ is deeper than that of $\mathrm{Ni}$, while the $\mathrm{HAZ}$ of $\mathrm{Ni} / \mathrm{Al}_{2} \mathrm{O}_{3}$ is much smaller than that of $\mathrm{Ni}$. Scale bars, $1 \mu \mathrm{m}$ in $\mathbf{a}, \mathbf{b}$ and $2 \mu \mathrm{m}$ in $\mathbf{c}, \mathbf{d}$. 
a $20^{\circ} \mathrm{C}$

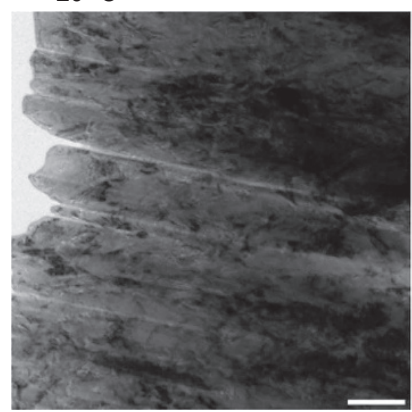

d $600{ }^{\circ} \mathrm{C}$

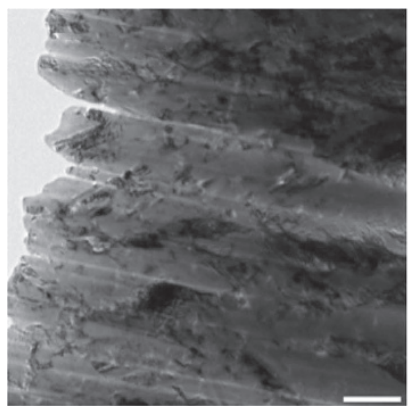

b $200^{\circ} \mathrm{C}$

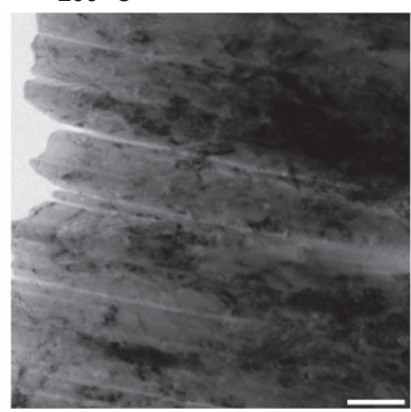

e $800^{\circ} \mathrm{C}$

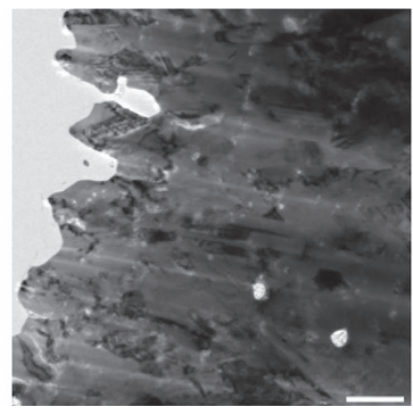

C $400^{\circ} \mathrm{C}$

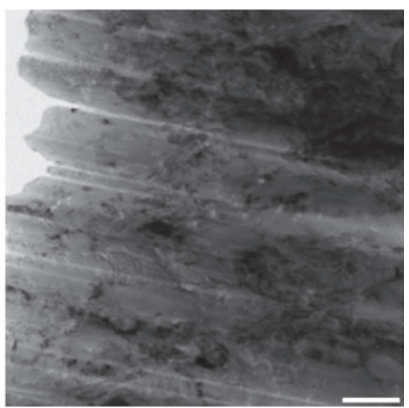

f $800^{\circ} \mathrm{C}$ for $1 \mathrm{~min}$

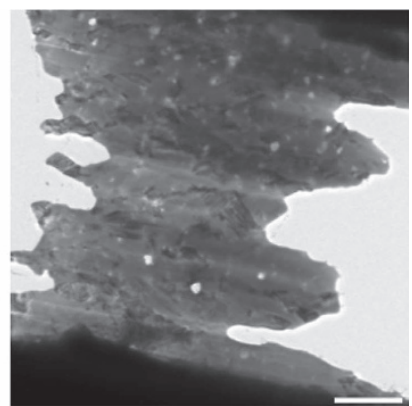

Figure 3 | Grain structure evolution of $\mathbf{N i} / \mathbf{A l}_{\mathbf{2}} \mathbf{O}_{\mathbf{3}}$. Transmission electron microscopy (TEM) images at $20^{\circ} \mathrm{C}(\mathbf{a}), 200^{\circ} \mathrm{C}(\mathbf{b}), 400{ }^{\circ} \mathrm{C}(\mathbf{c}), 600{ }^{\circ} \mathrm{C}(\mathbf{d})$, $800^{\circ} \mathrm{C}$ (e) and after $1 \mathrm{~min}$ at $800^{\circ} \mathrm{C}(\mathbf{f})$. The grains of $\mathrm{Ni} / \mathrm{Al}_{2} \mathrm{O}_{3}$ appear as columnar and maintain stable until the sample is heated up to $800^{\circ} \mathrm{C}$. The columnar grain boundaries vanish and grow in the through-thickness direction after the temperature increases to $800{ }^{\circ} \mathrm{C}$. Scale bars, $500 \mathrm{~nm}$ in a-e and $1 \mu \mathrm{m}$ in $\mathbf{f}$.

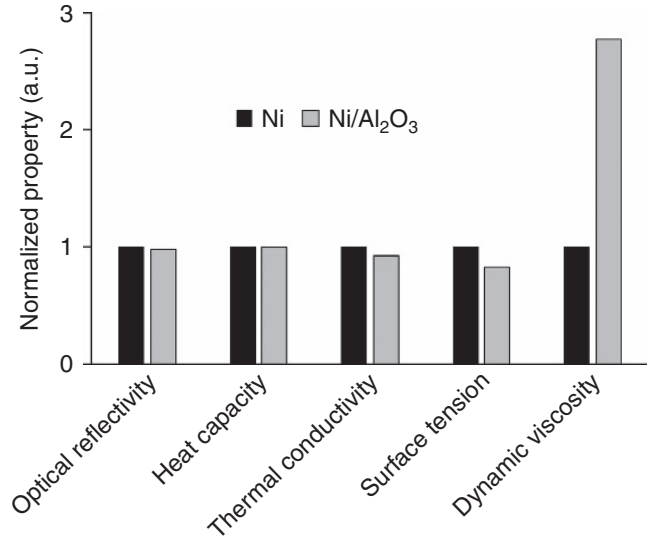

Figure 4 | Normalized material properties of $\mathrm{Ni}$ and $\mathrm{Ni} / \mathrm{Al}_{2} \mathrm{O}_{3}$. The material properties are normalized using $\mathrm{Ni}$ as a baseline to show the difference between $\mathrm{Ni}$ and $\mathrm{Ni} / \mathrm{Al}_{2} \mathrm{O}_{3}$. Optical reflectivity and heat capacity of $\mathrm{Ni} / \mathrm{Al}_{2} \mathrm{O}_{3}$ are very close to those of $\mathrm{Ni}$. Thermal conductivity and surface tension of $\mathrm{Ni} / \mathrm{Al}_{2} \mathrm{O}_{3}$ are lower than those of $\mathrm{Ni}$ while dynamic viscosity of $\mathrm{Ni} / \mathrm{Al}_{2} \mathrm{O}_{3}$ is significantly higher than that of $\mathrm{Ni}$.

those of $\mathrm{Ni}$ as baselines, which are plotted in Fig. 4. The optical reflectivity and heat capacity are not affected much by the nanoparticles while the thermal conductivity and surface tension are reduced and the dynamic viscosity is significantly increased. Some details of the measurement results are presented in Supplementary Note 1 and Supplementary Fig. 1.

With all these critical material properties available, numerical simulations were performed to understand the effects of nanoparticles on the heat transfer and fluid flow processes and thus the mechanisms for the metallurgical changes. A coupled heat transfer and fluid flow model was developed and validated for laser melting of metals in previous study ${ }^{25}$. It is a two- dimensional axisymmetric transient model based on finite element method. The model is used in the present work to predict the effects of nanoparticles on the heat transfer and fluid flow (that is, Marangoni flow) by using the nanoparticle-modified thermophysical properties. Basically, the nanoparticles change the thermophysical properties and consequently the heat transfer and fluid flow. The input parameters for the numerical model are the actual process parameters and the measured optical and thermophysical properties. The values of these parameters and properties are summarized in Supplementary Table 1. The model predicts the transient temperature field as a function of time and location, based on which the evolution of the MZ and the HAZ can be derived.

The predicted results for the $\mathrm{Ni}$ and $\mathrm{Ni} / \mathrm{Al}_{2} \mathrm{O}_{3}$ samples are shown in Fig. 5. The implication from the model coincides with the experimental results: the $\mathrm{MZ}$ is increased while the HAZ is decreased by the nanoparticles. The numerical model successfully captures the effects of nanoparticles on the heat transfer, melt pool flow and microstructure development using the effective optical and thermophysical properties.

The numerical simulation is insightful to understand the mechanisms responsible for the evolution of the distinct microstructures between $\mathrm{Ni}$ and $\mathrm{Ni} / \mathrm{Al}_{2} \mathrm{O}_{3}$. The model shows that the maximum surface temperature of $\mathrm{Ni} / \mathrm{Al}_{2} \mathrm{O}_{3}$ is higher than that of $\mathrm{Ni}$, indicating that the nanoparticles deepen the $\mathrm{MZ}$ by increasing the heat accumulation within the surface layer. The mitigation of the heat dissipation is further attributed to two mechanisms: (i) the nanoparticles reduce the thermal conductivity and thus decrease the conductive heat transfer to the base material and (ii) the nanoparticles significantly increase the viscosity and thereby suppress the thermocapillary flow and diminish the advective heat transfer within the melt pool. The mechanisms for the increased MZ and decreased HAZ by the nanoparticles are schematically summarized in Fig. 6. 

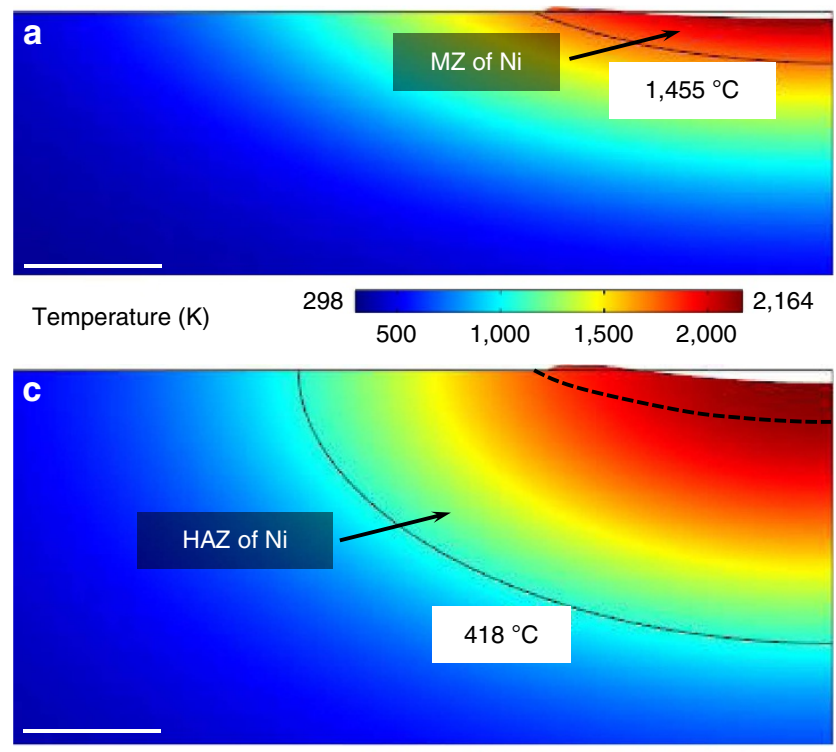

Temperature (K)
298

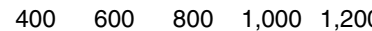

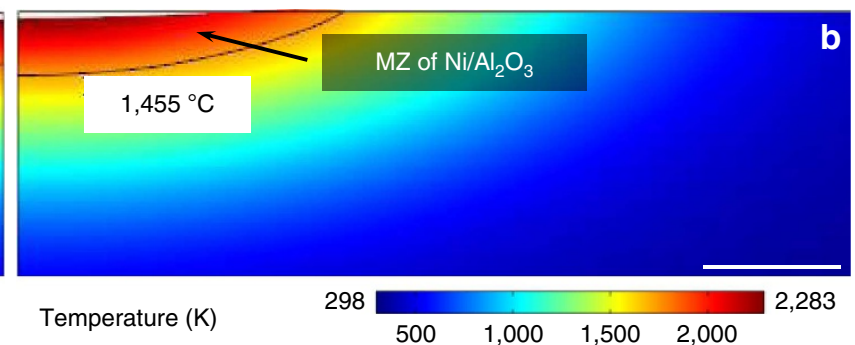

$500 \quad 1,000 \quad 1,500 \quad 2,000$

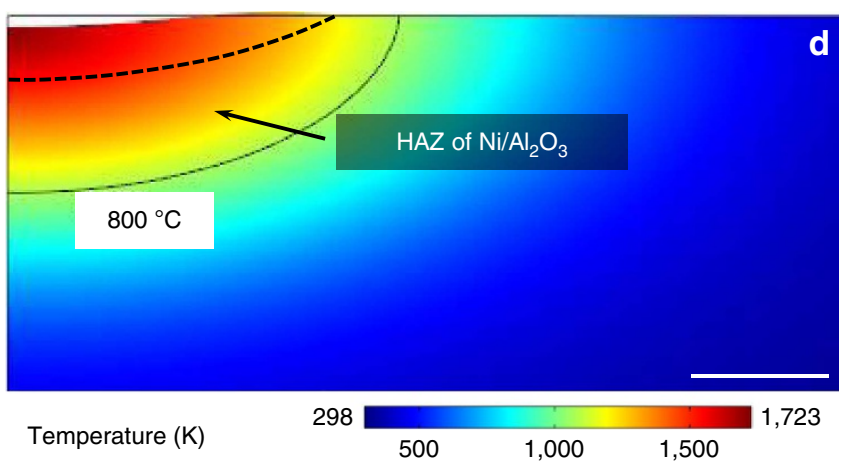

Figure 5 | Simulated melted zone (MZ) and heat-affected zone (HAZ) of $\mathbf{N i}$ and $\mathbf{N i} / \mathbf{A l}_{\mathbf{2}} \mathbf{O}_{\mathbf{3}}$. The predicted $\mathrm{MZs}$ of $\mathrm{Ni}(\mathbf{a})$ and $\mathrm{Ni} / \mathrm{Al} \mathrm{O}_{3}$ that were laser melted at a pulse energy of $0.18 \mathrm{~mJ}(\mathbf{b})$ and the corresponding $\mathrm{HAZs}$ of $\mathrm{Ni}(\mathbf{c})$ and $\mathrm{Ni} / \mathrm{Al}_{2} \mathrm{O}_{3}$ (d). The predicted $\mathrm{MZ}$ of $\mathrm{Ni} / \mathrm{Al} \mathrm{O}_{2} \mathrm{O}_{3}$ is deeper than that of $\mathrm{Ni}$, whereas the predicted $\mathrm{HAZ}$ of $\mathrm{Ni} / \mathrm{Al}_{2} \mathrm{O}_{3}$ is much smaller than that of $\mathrm{Ni}$, which agrees well with the experimental results in Fig. 2 . Scale bars, $5 \mu$ m in a-d.

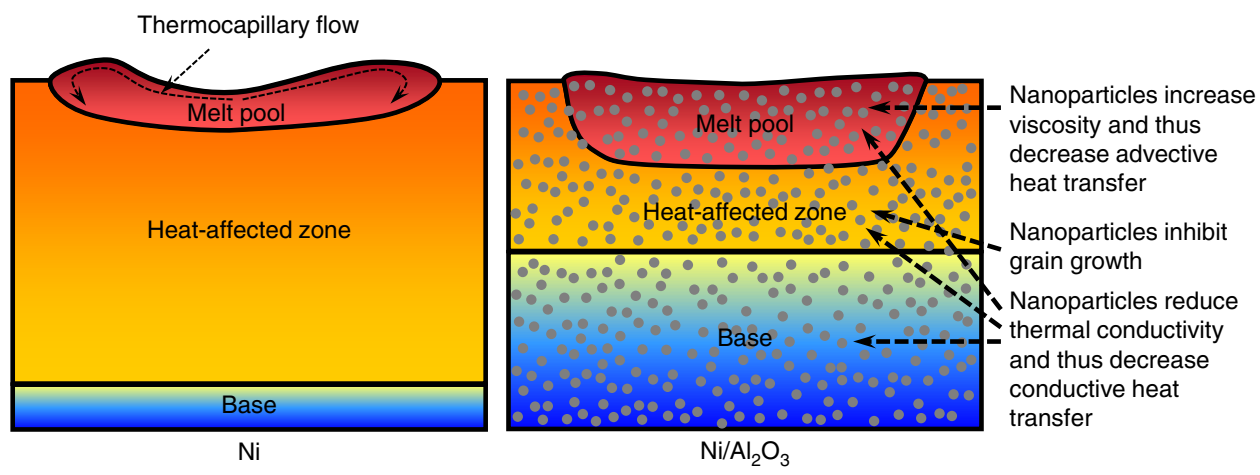

Figure 6 | Mechanisms for metallurgical modification by nanoparticles. The nanoparticles decrease the advective and conductive heat transfer to the bulk material and increase the heat accumulation within the melt pool, thereby increasing the melted zone (MZ) depth. The nanoparticles also prevent the grain growth and thus decrease the heat-affected zone (HAZ) size.

Effects of nanoparticle material and laser energy. To further validate that it was the nanoparticles that drove the metallurgical changes, the laser melting experiment was also conducted on $\mathrm{Ni}$ / $\mathrm{SiC}$ nanocomposite. The fraction of the $\mathrm{SiC}$ nanoparticles was 3.6 vol. \% and the average diameter was also $50 \mathrm{~nm}$. The experimental conditions were the same as those used for $\mathrm{Ni}$ and $\mathrm{Ni}$ / $\mathrm{Al}_{2} \mathrm{O}_{3}$. As shown in Fig. 7, the presence of $\mathrm{SiC}$ nanoparticles has the same effect as that of $\mathrm{Al}_{2} \mathrm{O}_{3}$ nanoparticles, that is, the nanoparticles increased the MZ and reduced the HAZ. Measurements of thermophysical properties were also performed for $\mathrm{Ni} / \mathrm{SiC}$. Thermal conductivity was reduced with the addition of $\mathrm{SiC}$ nanoparticles while dynamic viscosity was significantly increased. The specific measurement results are presented in Supplementary Note 1 and Supplementary Fig. 1. The effects of $\mathrm{SiC}$ nanoparticles on the thermophysical properties and the microstructure are consistent with those of $\mathrm{Al}_{2} \mathrm{O}_{3}$ nanoparticles.

In addition, the effects of laser pulse energy on the $\mathrm{MZ}$ depth and $\mathrm{HAZ}$ size were studied. Both $\mathrm{Ni}$ and $\mathrm{Ni} / \mathrm{Al}_{2} \mathrm{O}_{3}$ were laser melted at different energies (0.14-0.22 mJ), followed by the SEM and FIB characterization. The micrographs at different energies are shown in Supplementary Figs 2 and 3. In addition, the numerical simulations were performed at these energy levels. The measured and predicted $\mathrm{MZ}$ depth and $\mathrm{HAZ}$ size of $\mathrm{Ni}$ and $\mathrm{Ni} / \mathrm{Al}_{2} \mathrm{O}_{3}$ are plotted as functions of pulse energy in Fig. 8. The $\mathrm{MZ}$ and $\mathrm{HAZ}$ are enlarged for both materials as the pulse energy increases. The $\mathrm{Al}_{2} \mathrm{O}_{3}$ nanoparticles have the same effect at each energy level, that is, reducing the HAZ while increasing the MZ.

The predicted trends of the $\mathrm{MZ}$ and the $\mathrm{HAZ}$ for $\mathrm{Ni}$ and $\mathrm{Ni} / \mathrm{Al}_{2} \mathrm{O}_{3}$ agree well with the experimental results, although there are some differences in the exact values between the predictions and the measurements, especially for $\mathrm{Ni} / \mathrm{Al}_{2} \mathrm{O}_{3}$. Laser interactions with metals with the presence of nanoparticles involve rather complex physical phenomena. The numerical model does not take all the effects into account. For example, the laser melting process can change the fraction and the morphology of the nanoparticles and the interfacial bonding between the matrix and the nanoparticles, and thus the thermophysical properties ${ }^{26}$. Also, the thermophysical properties change with temperature, but the temperature-dependent properties of the nanocomposite are not available for the simulation. In addition, the model uses a set 
a

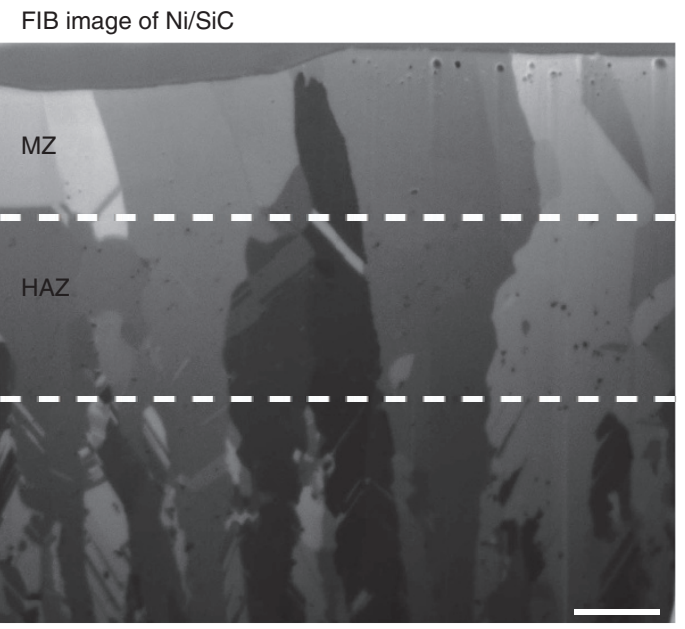

b Comparison among materials

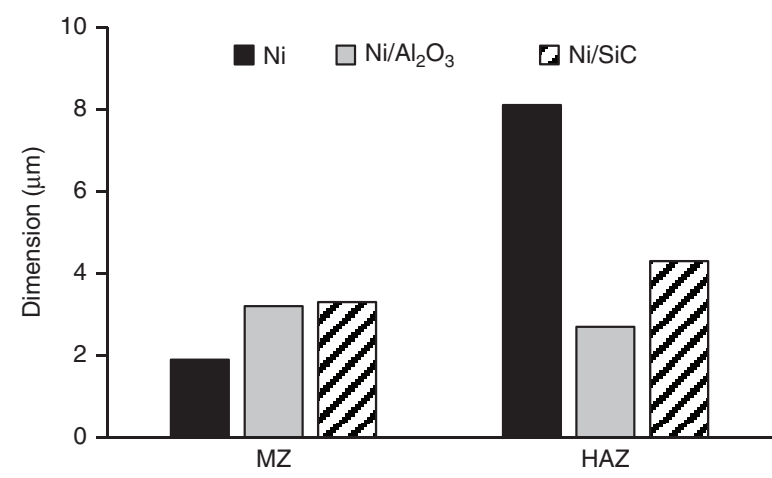

Figure 7 | Melted zone (MZ) and heat-affected zone (HAZ) of Ni/SiC.

Focused ion beam (FIB) micrographs of $\mathrm{Ni} / \mathrm{SiC}$ that was laser melted at a pulse energy of $0.18 \mathrm{~mJ}(\mathbf{a})$ and comparison with those of $\mathrm{Ni}$ and $\mathrm{Ni} / \mathrm{Al}_{2} \mathrm{O}_{3}$ (b). The $\mathrm{SiC}$ nanoparticles have the same effects as the $\mathrm{Al}_{2} \mathrm{O}_{3}$ ones: the presence of the nanoparticles increases the $\mathrm{MZ}$ depth while decreasing the HAZ size. Scale bar, $2 \mu \mathrm{m}$ in a.

temperature to predict the HAZ without considering the kinetics of the grain growth, which is probably the reason why the predicted increasing effects of pulse energy on HAZ are not as substantial as the experimental measurements. In reality, as the laser energy increases, not only does the region above the grain growth temperature increase, but also the duration for grain growth increases, which is not considered in the model. Despite these limitations of the numerical model, it provides insight into understanding the mechanisms of metallurgical changes introduced by the nanoparticles, which is the main objective of the simulation.

In conclusion, the microstructural and numerical studies showed that the nanoparticles reduced the heat dissipation in the laser melting process for a deeper $\mathrm{MZ}$ and meanwhile restricted the grain coarsening for a much smaller HAZ, which resolved a long-standing dilemma in the field of manufacturing. Although the present work demonstrates the feasibility to improve manufacturability of materials by nanoparticles, it will be interesting to perform a systematic study in the future on the effects of the material, size, morphology and fraction of nanoparticles on the thermophysical properties of nanocomposites and thus their manufacturability.

It will be of significance if this phenomenon can be extended to other laser processing technologies, such as laser welding and laser additive manufacturing, where the deterioration of the a $\mathrm{MZ}$ depth of $\mathrm{Ni}$ and $\mathrm{Ni} / \mathrm{Al}_{2} \mathrm{O}_{3}$

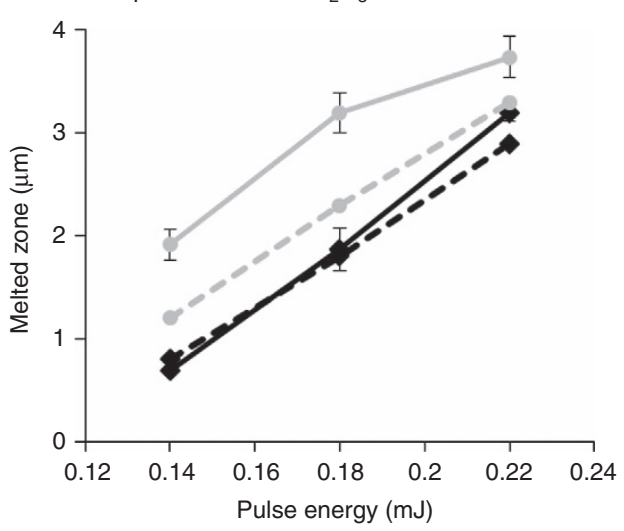

b $\mathrm{HAZ}$ size of $\mathrm{Ni}$ and $\mathrm{Ni} / \mathrm{Al}_{2} \mathrm{O}_{3}$

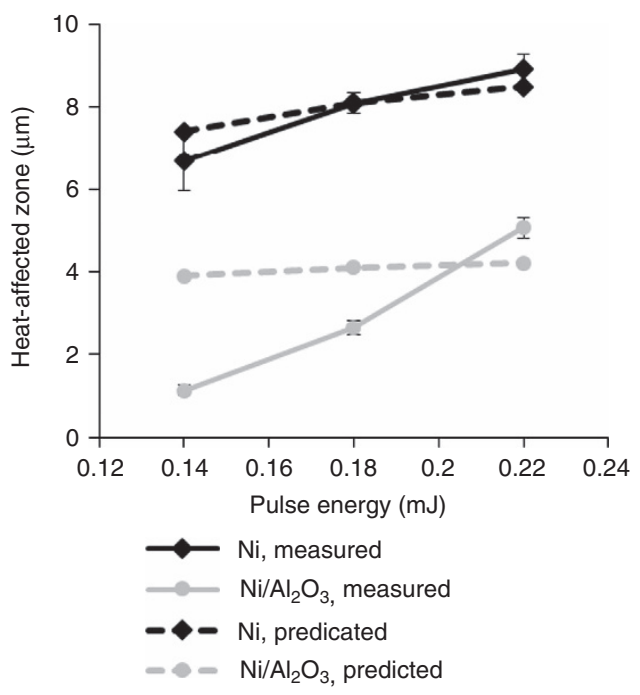

Figure 8 | Melted zone (MZ) depth and heat-affected zone (HAZ) size of $\mathbf{N i}$ and $\mathbf{N i} / \mathbf{A l}_{\mathbf{2}} \mathbf{O}_{\mathbf{3}}$. Measured and predicted $\mathrm{MZ}$ depth (a) and $\mathrm{HAZ}$ size (b) of $\mathrm{Ni}$ and $\mathrm{Ni} / \mathrm{Al}_{2} \mathrm{O}_{3}$ at different pulse energies. As the pulse energy increases, the $M Z$ and $H A Z$ become larger for both materials. The $M Z$ of $\mathrm{Ni} / \mathrm{Al}_{2} \mathrm{O}_{3}$ is larger than that of $\mathrm{Ni}$, whereas the $\mathrm{HAZ}$ of $\mathrm{Ni} / \mathrm{Al}_{2} \mathrm{O}_{3}$ is much smaller than that of $\mathrm{Ni}$ at each energy level. The numerical model successfully predicts the effects (trends) introduced by nanoparticles on $M Z$ and HAZ. The error bars in the measured MZ depths and HAZ sizes are the standard deviations calculated over five measurements.

microstructures and material properties of HAZ is a serious problem that limits the performance of the products. Although laser additive manufacturing is based on the melting of powder materials layer by layer and appears different from laser melting, both technologies share the same process physics, including heat transfer, fluid flow and microstructure evolution. Therefore, the proposed approach is applicable to laser additive manufacturing, that is, nanoparticles can be used to tune the melting and solidification processes and thereby improve the manufacturability of the materials. The approach will add another degree of freedom to enhance the capability and extend the application space of a manufacturing process.

\section{Methods}

Sample preparation. $\mathrm{Ni} / \mathrm{Al}_{2} \mathrm{O}_{3}$ and $\mathrm{Ni} / \mathrm{SiC}$ nanocomposites were prepared by electro-codeposition of $\mathrm{Ni}$ and the corresponding nanoparticles in a standard nickel Watts bath containing $10 \mathrm{gl}^{-1}$ of spherical nanoparticles with an average diameter of $50 \mathrm{~nm}$. The solution was mechanically mixed and ultrasonically 
processed for $2 \mathrm{~h}$ before electro-codeposition to achieve a uniform distribution and effective dispersion of the nanoparticles. Electro-codeposition was carried out for $2 \mathrm{~h}$ with the continuation of mechanical stirring and sonication to maintain the nanoparticle dispersion and distribution. The temperature was controlled at $43{ }^{\circ} \mathrm{C}$ and the current density was set at $1 \mathrm{~A} \mathrm{dm}^{-2}$. Pure $\mathrm{Ni}$ was also prepared under the same conditions for the comparison study.

Laser melting. The experimental setup of laser melting is schematically shown in Supplementary Fig. 4. A 1,070 nm, $200 \mathrm{~W}$ fibre laser (SPI Lasers SP-200C-A-S6A-C) was directed into a scan head (ScanLab HurryScan III $14 \mathrm{~mm}$ ). The scan head was furnished with an $\mathrm{f}$-theta objective with a focal length of $163 \mathrm{~mm}$, which resulted in a beam diameter of $\sim 49 \mu \mathrm{m}$ at the focal plane. The laser was pulsed at $100 \mathrm{kHz}$ with a pulse duration of $1.5 \mu$ s. The laser pulse energy was varied from 0.14 to $0.22 \mathrm{~mJ}$. A raster scan with a track spacing of $4 \mu \mathrm{m}$ and a scan speed of $0.4 \mathrm{~m} \mathrm{~s}^{-1}$ was performed to cover a square of $1 \mathrm{~mm} \times 1 \mathrm{~mm}$. Argon flow was applied during laser melting to minimize the oxidation. Pure $\mathrm{Ni}, \mathrm{Ni} / \mathrm{Al}_{2} \mathrm{O}_{3}$, and $\mathrm{Ni} / \mathrm{SiC}$ nanocomposites were laser melted to investigate the effects of nanoparticles on melting and solidification behaviours.

Sample characterization. Characterization of microstructures of $\mathrm{Ni} / \mathrm{Al}_{2} \mathrm{O}_{3}$ and $\mathrm{Ni} / \mathrm{SiC}$ was first carried out using scanning electron microscopy (SEM) facilitated with energy dispersive X-ray spectroscopy (EDS/EDX). EDS analysis was used to quantify the fraction of nanoparticles incorporated into the nanocomposites. The volume fraction of nanoparticles was estimated based on the atom fraction of the major element in the nanoparticles $(\mathrm{Al}$ or $\mathrm{Si})$ and the base metal $(\mathrm{Ni})$.

To characterize the melted zone (MZ) and the heat-affected zone (HAZ) of $\mathrm{Ni}$, $\mathrm{Ni} / \mathrm{Al}_{2} \mathrm{O}_{3}$, and Ni/SiC, the samples were sectioned using focused ion beam (FIB) milling, followed by SEM and FIB imaging. The MZ and HAZ were identified based on microstructural changes. The MZ was determined with two methods:

(i) it was identified using SEM by the reduction of the nanoparticles in $\mathrm{Ni} / \mathrm{Al}_{2} \mathrm{O}_{3}$ and $\mathrm{Ni} / \mathrm{SiC}$ nanocomposites and the introduction of tiny granular features in the pure $\mathrm{Ni}$ by laser melting and (ii) it was identified by the FIB characterization as the resolidified titled grains due to uneven heating and cooling. Both the methods agreed with each other. The HAZ was identified by the FIB imaging as the region with considerably coarsened grains compared with the original microstructure. The SEM or FIB image was first divided into five even strips perpendicular to the surface, after which the MZ or HAZ was determined on each strip. The mean and the standard deviation over the five measurements were then calculated and reported.

In situ heating transmission electron microscopy (TEM) characterization of $\mathrm{Ni} / \mathrm{Al}_{2} \mathrm{O}_{3}$ was facilitated by a micro-heater (DENSsolutions, Delft, Netherlands). The $\mathrm{Ni} / \mathrm{Al}_{2} \mathrm{O}_{3}$ sample for TEM was prepared by FIB milling.

Data availability. All relevant data are available from the authors.

\section{References}

1. Faghri, A. \& Zhang, Y. Transport Phenomena in Multiphase Systems (Elsevier, 2006).

2. Steen, W. M. Laser Material Processing (Springer, 2010).

3. Ready, J. F. \& Farson, D. F. LIA Handbook of Laser Material Processing (Laser Institute of America, 2001).

4. Katayama, S. Handbook of Laser Welding Technologies (Woodhead Publishing Limited, 2013).

5. Rawal, S. Metal-matrix composites for space applications. J. Metals 53, 14-17 (2001).

6. Crainic, N. \& Marques, A. T. Nanocomposites: a state-of-the-art review. Key Eng. Mater. 230-232, 656-659 (2002)

7. Jiang, Q. C., Li, X. L. \& Wang, H. Y. Fabrication of TiC particulate reinforced magnesium matrix composites. Scr. Mater. 48, 713-717 (2003).

8. Yang, Y., Lan, J. \& Li, X. Study on bulk aluminum matrix nano-composite fabricated by ultrasonic dispersion of nano-sized $\mathrm{SiC}$ particles in molten aluminum alloy. Mater. Sci. Eng. A 380, 378-383 (2004).

9. Low, C. T. J., Wills, R. G. A. \& Walsh, F. C. Electrodeposition of composite coatings containing nanoparticles in a metal deposit. Surf. Coat. Technol. 201, 371-383 (2006).

10. Cao, G., Konishi, H. \& Li, X. Mechanical properties and microstructure of $\mathrm{Mg} / \mathrm{SiC}$ nanocomposites fabricated by ultrasonic cavitation based nanomanufacturing. J. Manuf. Sci. Eng. 130, 031105 (2008).

11. Chen, L. et al. Novel nanoprocessing route for bulk graphene nanoplatelets reinforced metal matrix nanocomposites. Scr. Mater. 67, 29-32 (2012).

12. Ma, C. et al. Effect of fabrication and processing technology on the biodegradability of magnesium nanocomposites. J. Biomed. Mater. Res. B Appl. Biomater. 101B, 870-877 (2013).

13. Chen, L. et al. Processing and properties of magnesium containing a dense uniform dispersion of nanoparticles. Nature 528, 539-543 (2015).

14. Dadbakhsh, S. \& Hao, L. Effect of $\mathrm{Al}$ alloys on selective laser melting behaviour and microstructure of in situ formed particle reinforced composites. J. Alloys Compounds 541, 328-334 (2012).
15. Song, B. et al. Microstructure and tensile behavior of hybrid nano-micro SiC reinforced iron matrix composites produced by selective laser melting. J. Alloys Compd. 579, 415-421 (2013).

16. Biedunkiewicz, A. et al. Effect of milling time on thermal treatment of $\mathrm{TiC}, \mathrm{TiB}_{2} /$ steel powders. J. Therm. Anal. Calorim. 113, 379-383 (2013).

17. Gu, D., Wang, H. \& Zhang, G. Selective laser melting additive manufacturing of Ti-based nanocomposites: the role of nanopowder. Metall. Mater. Trans. A 45, 464-476 (2014).

18. Wang, B., Alam, M. T. \& Haque, M. A. Grain growth in nanocrystalline nickel films at low temperature and stress. Scr. Mater. 71, 1-4 (2014).

19. Poudel, B. et al. High-thermoelectric performance of nanostructured bismuth antimony telluride bulk alloys. Science 320, 634-638 (2008).

20. Biswas, K. et al. High-performance bulk thermoelectrics with all-scale hierarchical architectures. Nature 489, 415-418 (2012).

21. Vafaei, S., Purkayastha, A., Jain, A., Ramanath, G. \& Borca-Tasciuc, T. The effect of nanoparticles on the liquid-gas surface tension of $\mathrm{Bi}_{2} \mathrm{Te}_{3}$ nanofluids. Nanotechnology 20, 185702 (2009).

22. Corcione, M. Empirical correlating equations for predicting the effective thermal conductivity and dynamic viscosity of nanofluids. Energ. Convers. Manag. 52, 789-793 (2011).

23. Ma, C., Zhao, J., Cao, C., Lin, T. \& Li, X. Fundamental study on laser interactions with nanoparticles-reinforced metals-part I: effect of nanoparticles on optical reflectivity, specific heat, and thermal conductivity'. J. Manuf. Sci. Eng. 138, 121001 (2016)

24. Ma, C., Zhao, J., Cao, C., Lin, T. \& Li, X. Fundamental study on laser interactions with nanoparticles-reinforced metals-part II: effect of nanoparticles on surface tension, viscosity and laser melting. J. Manuf. Sci. Eng 138, 121002 (2016).

25. Ma, C., Vadali, M., Duffie, N. A., Pfefferkorn, F. E. \& Li, X. Melt pool flow and surface evolution during pulsed laser micro polishing of Ti6Al4V. J. Manuf. Sci. Eng. 135, 061023 (2013).

26. Zheng, R., Gao, J., Wang, J. \& Chen, G. Reversible temperature regulation of electrical and thermal conductivity using liquid-solid phase transitions. Nat. Commun. 2, 289 (2011).

\section{Acknowledgements}

This work was supported by National Science Foundation. We thank Steve Rapp at RGS Scientific and Bob Sommerville at Angstrom Scientific Inc. for providing the microheater (DENSsolutions), and Noah Bodzin at UCLA Nanoelectronics Research Facility for his help with preparing the TEM samples.

\section{Author contributions}

X.L. and C.M. conceived the idea and designed the experimental plans. C.M. conducted the laser melting experiments and performed the numerical simulations. C.M., L.C. and C.C. conducted materials characterization. L.C. examined the nanoparticle-enabled stabilization of microstructure by in situ heating transmission electron microscopy. X.L., C.M. and L.C. interpreted the experimental data. C.M, L.C. and X.L. contributed to the writing of the paper. X.L. supervised the whole work.

\section{Additional information}

Supplementary Information accompanies this paper at http://www.nature.com/ naturecommunications

Competing financial interests: The authors declare no competing financial interests.

Reprints and permission information is available online at http://npg.nature.com/ reprintsandpermissions/

How to cite this article: Ma, C. et al. Nanoparticle-induced unusual melting and solidification behaviours of metals. Nat. Commun. 8, 14178 doi: 10.1038/ncomms14178 (2017).

Publisher's note: Springer Nature remains neutral with regard to jurisdictional claims in published maps and institutional affiliations.

This work is licensed under a Creative Commons Attribution 4.0 International License. The images or other third party material in this article are included in the article's Creative Commons license, unless indicated otherwise in the credit line; if the material is not included under the Creative Commons license, users will need to obtain permission from the license holder to reproduce the material. To view a copy of this license, visit http://creativecommons.org/licenses/by/4.0/

C) The Author(s) 2017 